УДК 347.961.6

\title{
НЕКОТОРЫЕ ОСОБЕННОСТИ ДИСЦИПЛИНАРНОЙ ОТВЕТСТВЕННОСТИ НОТАРИУСА И ПРОБЛЕМЫ, СВЯЗАННЫЕ С ЛИШЕНИЕМ НОТАРИУСА ПРАВА НОТАРИАЛЬНОЙ ДЕЯТЕЛЬНОСТИ
}

Галкина Анастасия Валериевна Цуцкарева Анастасия Александровна студенты Скачкова Ольга Сергеевна к.ю.н., доцент

ФГБОУ ВО «Самарский государственный экономический университет»

Аннотация: Статья посвящена особенностям дисциплинарной ответственности нотариуса. Особое внимание уделено такой исключительной мере дисциплинарной ответственности как лишение права нотариальной деятельности. В статье рассмотрены теоретические положения дисциплинарной ответственности нотариуса, проведен анализ судебной практики по вопросам обжалования решений нотариальных палат, а также обширный анализ по делам о лишении права нотариальной деятельности. В результате проведенных анализов выявлены проблемы и предложены некоторые изменения в законодательство.

Ключевые слова: нотариус, нотариальная палата, ответственность, дисциплинарная ответственность, дисциплинарные проступки, лишение права нотариальной деятельности.

SOME FEATURES OF THE NOTARY'S DISCIPLINARY RESPONSIBILITY AND PROBLEMS RELATED TO THE DEPRIVATION OF THE NOTARY'S RIGHT TO NOTARIAL ACTIVITY

\section{Galkina Anastasiya Valerievna Tsutskareva Anastasiya Aleksandrovna Skachkova Olga Sergeevna}

Abstract: The article is devoted to the peculiarities of the notary's disciplinary responsibility. Special attention is paid to such an exceptional measure of disciplinary 


\section{НАУКА, ОБЩЕСТВО, КУЛЬТУРА: ПРОБЛЕМЫ И ПЕРСПЕКТИВЫ ВЗАИМОДЕЙСТВИЯ В СОВРЕМЕННОМ МИРЕ}

responsibility as the deprivation of the right to notarial activity. The article considers the theoretical provisions of the notary's disciplinary responsibility, analyzes the judicial practice on appeals against decisions of notary chambers, as well as an extensive analysis of cases of deprivation of the right to notarial activity. As a result of the conducted analyses, problems were identified and some changes to the legislation were proposed.

Key words: notary, notary chamber, responsibility, disciplinary responsibility, disciplinary offenses, deprivation of the right to notarial activity.

Как известно, в настоящее время в каждом субъекте РФ существует немалое количество частнопрактикующих нотариусов. Государственных нотариусов на территории РФ практически не осталось.

К примеру, на территории Самарской области, согласно сведениям Управления Министерства Юстиции РФ по Самарской области, насчитывается 145 нотариусов [1].

Нотариус, что важно отметить, очень ответственная и требующая полной отдачи профессия. Задаваясь вопросом о контролирующих органах, которые надзирают за деятельностью нотариусов и в случае нарушений последними как Основ законодательства о нотариате, Кодекса профессиональной этики нотариуса [2], методических рекомендаций по нотариальной деятельности, а также уголовного, налогового и гражданского права, то стоит отметить, что данные контролирующие органы как раз подразделяются в зависимости от вида ответственности, к которой может быть привлечен нотариус.

Систематический контроль со стороны государства за деятельностью нотариусов осуществляется посредством проведения проверок силами территориального управления Министерства юстиции и нотариальной палаты соответствующего субъекта РФ. Как правило, созданная комиссия состоит из членов - представителей вышеуказанных органов. Проверки в свою очередь подразделяются как на плановые, так и внеплановые. Исходя из положений статьи 34 Основ законодательства о нотариате [3], плановая проверка организации работы нотариуса проводится один раз в четыре года. Наиболее подробно положения о проверке содержатся в методических рекомендациях [4].

Нотариальные палаты субъектов, конечно, более плотно взаимодействует с нотариусами, предмет их ведения касаемо контрольной функции гораздо шире остальных органов. При выявлении нарушений нотариус привлекается к 


\section{НАУКА, ОБЩЕСТВО, КУЛЬТУРА: ПРОБЛЕМЫ И ПЕРСПЕКТИВЫ ВЗАИМОДЕЙСТВИЯ В СОВРЕМЕННОМ МИРЕ}

дисциплинарной ответственности. Данный вид ответственности чаще всего применяется к нотариусам, как правило, какие-либо нарушения Кодекса профессиональной этики нотариуса квалифицируются как дисциплинарные проступки, перечень которых достаточно широк. Мерами дисциплинарной ответственности нотариуса являются замечание, выговор, строгий выговор.

Поводом и основанием к возбуждению дисциплинарного производства могут стать обстоятельства, закрепленные в пункте 9.2 Кодекса профессиональной этики (например, нарушение правил и порядка совершения нотариальных действий, установленных законодательством; нарушение правил нотариального делопроизводства; нарушение тайны совершения нотариального действия и др.).

Поскольку дисциплинарная ответственность применяется к нотариусам достаточно часто, судебная практика содержит немало решений, в которых оспариваются решения правления нотариальных палат по дисциплинарному производству нотариусом, привлеченным к дисциплинарной ответственности.

Возникает вопрос, чем может быть чревато наличие дисциплинарных проступков в отношении нотариуса. Ответом на данный вопрос является п. 3 ч. 5 ст. 12 Основ законодательства РФ о нотариате, согласно которому неоднократные дисциплинарные проступки со стороны нотариуса являются основанием для его освобождения от полномочий на основании решения суда о лишении его права нотариальной деятельности.

В данном контексте необходимо упомянуть, что Кодекс профессиональной этики допускает снятие дисциплинарной ответственности. Причем никаких особых оснований для снятия не предусмотрено, необходимо только в случае, если в отношении нотариуса объявлено замечание - не совершать нового дисциплинарного проступка в течение года, если же объявлен выговор - не совершать дисциплинарных проступков в течение двух лет, при строгом выговоре не допускается совершение дисциплинарных проступков в течение пяти лет.

Кроме того, Кодексом предусмотрен случай добросовестного исполнения нотариусом своих профессиональных обязанностей и активного участия в деятельности профессионального сообщества, что предполагает при условии отсутствия повторного совершения проступков и наличия безупречного поведения снятие дисциплинарного взыскании ранее сроков, которые были описаны выше (но не ранее трех месяцев со дня наложения дисциплинарного взыскания). Инициатором в данном случае может быть либо само Правление 


\section{НАУКА, ОБЩЕСТВО, КУЛЬТУРА: ПРОБЛЕМЫ И ПЕРСПЕКТИВЫ ВЗАИМОДЕЙСТВИЯ В СОВРЕМЕННОМ МИРЕ}

нотариальной палаты, либо нотариус, подавший в нотариальную палату соответствующее заявление. В данном случае законодатель предусмотрел срок, после которого может быть снят

Таким образом, дисциплинарное взыскание является особой санкцией для нотариуса, неоднократное объявление которых может привести нотариуса к утрате его статуса, иными словами, к лишению права нотариальной деятельности.

В судебной практике встречаются дела, где нотариусы обращаются с исковым заявлением к нотариальной палате соответствующего субъекта РФ о признании незаконным привлечения нотариуса к дисциплинарной ответственности и отмене решения Правления нотариальной палаты, которым нотариус был привлечен к дисциплинарной ответственности.

Так, в одном из судебных дел [5] нотариус обратилась с аналогичным вышеуказанному иском к нотариальной палате. Нотариусу был вменен дисциплинарный проступок - замечание за несоблюдение культуры поведения при осуществлении профессиональной деятельности нотариуса. Однако, нотариусу-истцу удалось доказать, что не были установлены конкретные действия нотариуса, содержащие признаки вмененного ей дисциплинарного проступка. Суд пришел к выводу, что комиссия по профессиональной этикет нотариуса не установила фактов неуважительного поведения нотариуса, не установила фактов отказа от общения с заявителем, не установила фактов отказа приема документов на личном приеме, в связи с чем исковое заявление нотариуса было удовлетворено, на основании чего было отменено и признано незаконным решение о привлечении ее к дисциплинарной ответственности в виде замечания.

По данной категории дел, как мы видим, требуется доказать обратное той мотивировке и пункту Кодекса профессиональной этики, которые были указаны в решении комиссии, которым нотариус был привлечен к дисциплинарной ответственности.

Значительное количество дел существует в судебной практике, в которых нотариальная палата соответствующего субъекта РФ обращается с исковым заявлением к нотариусу о лишении права нотариальной деятельности. Указанная категория дел является разнообразной и интересной, поскольку в ней подробно расписываются нарушения, которые были совершены нотариусом, описаны неоднократные привлечения к дисциплинарной ответственности. 


\section{НАУКА, ОБЩЕСТВО, КУЛЬТУРА: ПРОБЛЕМЫ И ПЕРСПЕКТИВЫ ВЗАИМОДЕЙСТВИЯ В СОВРЕМЕННОМ МИРЕ}

В одном из дел [6] Нотариальная палата Удмуртской Республики обратилась в суд с иском к нотариусу о лишении права нотариальной деятельности. Истец мотивировал свои требования тем, что выявленные нарушения нотариальной деятельности носили систематический характер. В частности, нарушения касались неистребования при удостоверении сделок сведений о зарегистрированных лицах в жилых помещениях, сведений о собственниках, содержащихся в ЕГРН, сведений о банкротстве, неистребование сведений о наличии судебного акта о недееспособности лица, совершающего сделку. Указанные нарушения, как верно отметил суд, неизбежно могут привести к нарушению прав граждан. Кроме того, множество нарушений касались правил нотариального делопроизводства.

Важно отметить, что в данном деле все нарушения по большей части были обнаружены в ходе плановой проверки в 2018 году, где было также выяснено, что нарушений, обнаруженные предыдущей плановой проверкой в 2014 году, так и не были устранены в полном объеме. Аналогичная ситуация была и при проверке в 2018 году, когда комиссия выявила нарушения и установила срок для их устранения, но они снова не были устранены в полном объеме. При рассмотрении дела, судом было установлено, что нотариус имеет шесть непогашенных дисциплинарных взысканий в форме строгих выговоров. Для исправления выявленных недостатков со стороны нотариальной палаты нотариусу предоставлялось время, но недостатки не были устранены.

По итогу, суд, установив, что нотариусом в период его профессиональной деятельности были нарушены требования законодательства (в частности, семейного, гражданского, требования, касающиеся нотариального делопроизводства), а также принял во внимание неоднократное привлечение его к дисциплинарной ответственности, в результате, оценив все доводы в совокупности, решил удовлетворить иск нотариальной палаты и лишить нотариуса права нотариальной деятельности. Данное решение было обжаловано ответчиком - бывшим нотариусом, дошло до Шестого кассационного суда общей юрисдикции, однако было оставлено последним без изменения.

Еще одним интересным решением суда нотариус также был лишен права нотариальной деятельности по иску Ассоциации нотариусов «Нотариальная палата Республики Дагестан» [7]. Причем основанием для обращения в суд с данным заявлением послужило невнесение информации в ЕИС за 2 и 3 кварталы 2016 года без уважительной причины. 


\section{НАУКА, ОБЩЕСТВО, КУЛЬТУРА: ПРОБЛЕМЫ И ПЕРСПЕКТИВЫ ВЗАИМОДЕЙСТВИЯ В СОВРЕМЕННОМ МИРЕ}

До этого нотариальная палата проводила внеплановую проверку деятельности нотариуса, при проведении которой было установлено невнесение сведений в ЕИС, на основании чего было возбуждено дисциплинарное производство в отношении ответчика. К тому же разумные сроки причины неисполнения требований законодательства о нотариате ответчиком не были устранены.

Однако, что важно отметить, что со стороны нотариальной палаты к направлялось обращение, где истец уведомил ответчика о том, что к нему в нотариальную контору будет направлен системный администратор нотариальной палаты для установки и наладки ЕИС, чтобы он обеспечил доступ в нотариальную контору и к компьютерной технике, с выходом в сеть интернет. Однако быстро осуществить всю установку не удалось, в судебном решении не указано, по какой причине.

В данном деле ответчик пояснял, что причиной не своевременного внесения сведений в ЕИС являлось выход из строя компьютерной техники и отсутствие соответствующей программы.

Указанные нарушения, допущенные нотариусом, суд расценил как существенные, нарушающие действующее законодательство, что в силу ст. 12 «Основ законодательства Российской Федерации о нотариате», что является основанием для лишения ответчика права нотариальной деятельности.

Анализ данного судебного решения подтверждает, что в нем отсутствуют ссылки на ранее установленные дисциплинарные проступки со стороны ответчика. Однако, в решении указано на обращение Центра инноваций и информационных технологий к истцу с информированием последнего о непредставлении сведений в ЕИС за 2 и 3 кварталы 2016 года. Получается, что бывший нотариус полгода не вносил сведения в ЕИС без каких-либо уважительных причин. И, несомненно, еще одним немаловажным основанием для обращения нотариальной палаты в суд с соответствующим иском послужило письмо Президента Федеральной нотариальной палаты с требованием незамедлительно принять меры и на основании п.3 ч.5 ст. 12 Основ законодательства РФ о нотариате обратиться в суд с ходатайством о лишении нотариуса права нотариальной деятельности за невнесение информации в ЕИС за 2 и 3 кварталы 2016 года без уважительной причины.

Таким образом, указанная судебная практика свидетельствует о том, что нотариус должен соответствовать всем профессиональным требованиям, в том числе и идти в ногу со временем, а именно подстраиваться под все изменения 


\section{НАУКА, ОБЩЕСТВО, КУЛЬТУРА: ПРОБЛЕМЫ И ПЕРСПЕКТИВЫ ВЗАИМОДЕЙСТВИЯ В СОВРЕМЕННОМ МИРЕ}

законодательства, не игнорировать цифровизацию нотариальной деятельности, а наоборот способствовать изучению процесса электронного нотариата и его внедрения в свою профессиональную деятельность. Кроме того, такие масштабные изменения в области нотариата, как его цифровизация, как правило, вводятся не оперативно, а постепенно, о чем нотариальные палаты, несомненно, неоднократно уведомляют нотариусов и проводят соответствующие обучения.

Анализ судебной практики по делам о лишении нотариусов права нотариальной деятельности показал, что резолютивная часть многих решений содержит выводы суда и дополнительное требование о сдаче гербовой печати нотариуса, нотариального архива, согласно номенклатуре дел.

Ввиду данного требования интересной показалась практика судов, расположенных в городе Кемерово.

Согласно решения Рудничного районного суда г. Кемерово были удовлетворены исковые требования Кемеровской областной нотариальной палаты (Ассоциации) к нотариусу о лишении права нотариальной деятельности нотариуса, изъятии гербовой печати нотариуса, лицензии на право нотариальной деятельности, нотариального архив удовлетворены. Указанное решение устояло в апелляционной инстанции и вступило в силу 25.08.2016 года.

Далее Решением Кемеровского районного суда Кемеровской области от 13.12.2016 принудительно изъяты у бывшего нотариуса с места осуществления им нотариальной деятельности нотариальный архив нотариуса Кемеровского нотариального округа Кемеровской области, занимавшегося частной практикой; государственный архив Пятой Кемеровской государственной нотариальной конторы; неиспользованные, испорченные, продублированные или имеющие технический брак бланки для совершения нотариальных действий и переданы в Кемеровскую областную нотариальную палату (Ассоциацию); личная печать нотариуса, занимавшегося частной практикой, которая после была передана в Управление Минюста России по Кемеровской области.

Указанные выше сведения стали известны из анализа судебного акта [8], в котором рассматривался уже другие требования в том числе и к бывшему нотариусу.

Как установил суд, нотариус, который был лишен права нотариально деятельности, не исполнил в добровольном порядке вышеуказанные решения 


\section{НАУКА, ОБЩЕСТВО, КУЛЬТУРА: ПРОБЛЕМЫ И ПЕРСПЕКТИВЫ ВЗАИМОДЕЙСТВИЯ В СОВРЕМЕННОМ МИРЕ}

суда, тем самым вопреки ст. 16 Основ законодательства РФ о нотариате создал препятствия физическим лицам в осуществлении их прав и защите законных интересов, создал невозможность доступа к нотариальному архиву нотариуса.

Дело в том, что Управление Министерства юстиции Кемеровской вынесло соответствующий приказ "О передаче нотариального архива", согласно которому бывший нотариус должен был передать другому действующему нотариусу на временное хранение архив, который был сформирован им в период его деятельности и организовать передачу нотариального архива не позднее 25.10.2016, оформив передачу актами приема - передачи.

В силу того, что данный приказ бывшим нотариусом не был исполнен, ряд граждан столкнулись с проблемами.

Во-первых, об этом свидетельствует решение суда, где граждане обратились в суд с исковым заявлением о взыскании денежных средств с депозитного счета нотариуса. Ответчиками в данном деле истец указал бывшего нотариуса, нотариуса, которому якобы должен был быть передан архив нотариуса, а также банк, где был отрыт депозитный счет нотариуса.

Суд установил, что нотариальный архив нотариуса не изъят и не передан комиссии в связи с уклонением бывшего нотариуса от исполнения решения суда, кроме того, суд указал, что требования должны быть предъявлены к бывшему нотариусу, поскольку архив не был передан.

Однако гражданским законодательством предусмотрено, что списание денежных средств со счета осуществляется банком на основании распоряжения клиента.

Однако бывший нотариус лишен возможности дать распоряжение о выдаче денежных средств истцам, поскольку он лишен права нотариальной деятельности. По итогу суд решил удовлетворить требования истцов, убедившись, что остаток денежных средств на депозитном счете бывшего нотариуса, открытого в банке, достаточен для удовлетворения требований.

В данном случае исполнимость данного судебного акта, вероятно, была затянута, поскольку в решении суда указано, что у данного банка была отозвана лицензия на осуществление банковских операций.

Однако, это еще не все проблемы, выявленные при анализе судебной практики при неисполнении бывшим нотариусом требования суда о передаче нотариального архива. 


\section{НАУКА, ОБЩЕСТВО, КУЛЬТУРА: ПРОБЛЕМЫ И ПЕРСПЕКТИВЫ ВЗАИМОДЕЙСТВИЯ В СОВРЕМЕННОМ МИРЕ}

В суд обратилась гражданка с иском о признании права собственности на земельный участок [9], мотивировав свои требования тем, что после смерти ее супруга она обратилась в нотариальную контору нотариуса за получением свидетельства о праве на наследство, но получить его не может, поскольку нотариус лишен права нотариальной деятельности, и при этом нотариальный архив не изъят и не передан комиссии ввиду умышленного уклонения Тарасова С.В. от исполнения судебных решений, в связи с чем у нее отсутствует возможность оформить свои права на наследственное имущество. Судом был удовлетворен данный иск и за истцом было признано право собственности в порядке наследования.

Аналогичные решения, к сожалению, встречаются и в случае уклонения других лиц, которые были лишены права нотариальной деятельности, от передачи нотариального архива.

Анализ вышеуказанных решений по Кемеровской области показал, что из-за непередачи нотариального архива граждане, которые ранее обращались в нотариальную контору бывшего нотариуса, вынуждены посредством обращения в суды защищать свои права.

Кроме того, бывший нотариус, уклонившийся от передачи нотариального архива, рискует своим финансовым состоянием, поскольку, кроме того, что исковые требования заявителей удовлетворяются судом, так еще суд присуждает возместить судебные расходы с бывшего нотариуса.

Вышесказанное свидетельствует о том, что на законодательном уровне следует установить уголовную ответственность за уклонение передачи нотариального архива в установленный срок. Необходимо, во-первых, установить данное наказание, а также определить санкцию вплоть до лишения свободы сроком до 3 лет, поскольку нотариус законодательством РФ наделяется особыми полномочиями, и ему отводится серьезная роль, предъявляются соответствующие требования, в том числе и требования по хранению документов, что исключает по своей сути уклонение лица, который ранее являлся нотариусом, от передачи нотариального архива.

Судебная практика также содержит случаи, когда судом было отказано в иске Нотариальной палаты к нотариусу о лишении права нотариальной деятельности. Из анализируемого решения суда [10] стало ясно, что основанием для подачи данного иска стала поступившая из прокуратуры жалоба физического лица, которое обосновало свою жалобу тем, что нотариус удостоверила предварительный договор, одна из сторон по которой 


\section{НАУКА, ОБЩЕСТВО, КУЛЬТУРА: ПРОБЛЕМЫ И ПЕРСПЕКТИВЫ ВЗАИМОДЕЙСТВИЯ В СОВРЕМЕННОМ МИРЕ}

действовала по доверенности, срок по которой истек. В результате чего правам и законным интересам заявителя жалобы причинен существенный вред, выразившийся в причинении имущественного ущерба на сумму 800000 руб., переданные им по указанной сделке, который в последующем совершил их хищение.

Несмотря на указание истца, помимо вышеуказанного серьезного нарушения, на наличие дисциплинарных взысканий в отношении нотариуса, суд установил, что по истечению времени они считаются снятыми, согласно действующему законодательству.

Свою вину нотариусу удалось загладить, им было предложено добровольно возместить причиненный ущерб лицу, подавшему жалобу в прокуратуру (риск гражданской ответственности нотариуса застрахован в соответствии с полисом страхования на сумму 5000000 руб.).

В пользу позиции ответчика в данном деле были представлены справки по результатам комплексной плановой проверки профессиональной деятельности и исполнении Правил нотариального делопроизводства за 2016 г., откуда следует, что деятельность нотариуса признана удовлетворительной. Кроме того, суд принял во внимание, что Президентом Нотариальной палаты за долголетний труд и в связи с юбилейной датой со дня работы в нотариате нотариусу в 2016 г. была объявлена благодарность.

Оценив все обстоятельства, суд пришел к выводу, что привлечение нотариуса к исключительной мере дисциплинарной ответственности в виде лишение права занятия нотариальной деятельностью не будет отвечать критериями разумности, соразмерности и справедливости и не будет соответствовать тяжести допущенного им нарушения законодательства.

Указанное решение было обжаловано в апелляционную инстанцию, однако было оставлено последней без изменения.

Вышеуказанные проанализированные ситуации свидетельствуют о повышенной профессиональной роли нотариуса, случаи нарушения нотариусов законодательства и случаи лишения нотариуса права нотариальной деятельности подрывают доверие к институту нотариата в целом, являются в целом недопустимыми. Анализ показал, что нотариальные палаты не сразу идут на исключительную меру дисциплинарной ответственности в виде лишения права заниматься нотариальной деятельностью, a, напротив, предлагают устранить обнаруженные замечания в ходе проверок, предлагают пройти профессиональное обучение. 


\section{НАУКА, ОБЩЕСТВО, КУЛЬТУРА: ПРОБЛЕМЫ И ПЕРСПЕКТИВЫ ВЗАИМОДЕЙСТВИЯ В СОВРЕМЕННОМ МИРЕ}

Кроме того, было выявлено, что часть нотариусов, которые были лишены права нотариальной деятельности, имели значительный опыт в данной сфере (в некоторых из анализированных решениях судов было указание на выдачу лицензий на право нотариальной деятельности в 1994, 1995 гг.), что, казалось бы, ставит в сомнение проведенные ранее проверки в отношении нотариуса, а также возникает вопрос о том, почему по истечении 20 лет работы, возникают случаи лишения нотариуса права нотариальной деятельности за значительные и многочисленные нарушения законодательства. В заключении хотелось бы предложить более строгую систему назначения на должность нотариуса, более частое и тщательное проведение проверок на началах его самостоятельной работы.

\section{Список литературы}

1. Список нотариусов Самарской области // [электронный ресурс] URL: https://to63.minjust.gov.ru/ru/spisok-notariusov-samarskoy-oblasti (дата обращения 27.04.2021).

2. "Кодекс профессиональной этики нотариусов в Российской Федерации" (утв. Минюстом России 12.08.2019, 19.01.2016) (ред. от 23.04.2019) // СПС «Консультант Плюс».

3. Основы законодательства РФ о нотариате от 11 февраля 1993 г. N 4462-I (ред. от 30.12.2020) // Российская газета. 13 марта. 1993

4. Методические рекомендации по проведению проверки исполнения нотариусом, занимающимся частной практикой, профессиональных обязанностей (утв. Решением Правления ФНП от 17.06.2005, Протокол N 04/05) // СПС «Консультант Плюс».

5. Решение Ленинского районного суда г. Ярославля от 18 февраля 2020 г. по делу № 2-2208/2019 // [электронный pecypc] URL: https://sudact.ru/ regular/doc/mJR2CDNx0vlC/ (дата обращения 27.04.2021).

6. Решение Ленинского районного суда г. Ижевска Удмуртской Республики от 23 августа 2019 г. по дело N 2-1712/19 // [электронный ресурс] URL: https://sudact.ru/regular/doc/di8cLY9OAP5K/ (дата обращения 28.04.2021).

7. Решение Советского районного суда г. Махачкалы Республики Дагестан от 14 июня 2019 г. по делу № 2-2554/2019 // [электронный ресурс] URL: https://sudact.ru/regular/doc/EmUZiMMdUZrb/ (дата обращения 28.04.2021).

8. Решение Кемеровского районного суда Кемеровской области от 14 мая 2020 г. по делу № 2-892/2019 M-751/2019 // [электронный ресурс] URL: https://sudact.ru/regular/doc/TjdCrIyncR6B/ (дата обращения 28.04.2021). 
9. Решение Кемеровского районного суда Кемеровской области от 6 сентября 2019 г. по делу № 2-1039/2019 // [электронный ресурс] URL: https://sudact.ru/regular/doc/j05WQ8gy2lVJ/ (дата обращения 29.04.2021).

10. Решение Центрального районного суда г. Сочи от 5 октября 2017 г. по делу № 2-3850/2017 // [электронный pecypc] URL: https://sudact.ru/ regular/doc/GdUBugWEbsNR/ (дата обращения 29.04.2021). 